\title{
PW02-018 - Impact of PSTPIP1 mutaions on clinical phenotype
}

\author{
D Holzinger ${ }^{1,2^{*}}$, P Lohse ${ }^{3}$, S Faßl ${ }^{1}$, J Austermann ${ }^{1}$, T Vogl $^{1}$, W de Jager ${ }^{4}$, S Holland ${ }^{5}$, M Gattorno ${ }^{6}$, \\ C Rodriguez-Gallego ${ }^{7}$, J Arostegui ${ }^{8}$, S Fessatou ${ }^{9}, \mathrm{~B}$ Isidor $^{10}, \mathrm{~K} \mathrm{Ito}^{11}, \mathrm{H}-\mathrm{J}$ Epple $^{12}$, J Bernstein ${ }^{13}, \mathrm{M}$ Jeng ${ }^{13}, \mathrm{G} \mathrm{Lionetti}^{13}$ \\ , P Ong ${ }^{14}$, C Hinze $^{15}$, B Sampson $^{16}$, C Sunderkoetter ${ }^{17}$, D Foell ${ }^{2}$, J Chae ${ }^{18}$, A Ombrello ${ }^{18}$, J Brady ${ }^{18}$, I Aksentijevich ${ }^{18}$, \\ J Roth ${ }^{1}$
}

From 7th Congress of International Society of Systemic Auto-Inflammatory Diseases (ISSAID) Lausanne, Switerland. 22-26 May 2013

\section{Introduction}

Hyperzincaemia and hypercalprotectinaemia $(\mathrm{Hz} / \mathrm{Hc})$, a rare condition within the spectrum of autoinflammatory diseases, is associated with hepatosplenomegaly, arthritis, anemia, cutaneous inflammation, and failure to thrive. So far, no genetic cause has been identified. While the clinical appearance is heterogeneous, all affected individuals present with extremely elevated MRP8/MRP14 (calprotectin) serum concentrations (0.9-12.0 g/l (normal range $<0.001 \mathrm{~g} / \mathrm{l})$ ).

\section{Objectives}

The clinical phenotype of 12 patients was characterized and compared to 11 patients with classical PAPA syndrome. Screening of candidate genes was performed to identify disease-causing mutations.

\section{Methods}

Serum concentrations of MRP8/14 complex were analyzed in 12 patients with $\mathrm{Hz} / \mathrm{Hc}$ and compared to 11 PAPA patients. Candidate exons of these patients were sequenced. Cytokine profile of 12 patients with PSTPIP1 mutations was analyzed by mulitplex ELISA. MRP8/14 secretion from patient's PBMCs was measured and activity of patient's sera on monocytes evaluated. The clinical phenotype of all enrolled patients was characterized and compared.

\section{Results}

Ten of twelve patients were heterozygous carriers of a glutamic acid 250 (GAG) $\rightarrow$ lysine (AAG)/p.Glu250Lys/

${ }^{1}$ Institute of Immunology, University Hospital Muenster, Germany Full list of author information is available at the end of the article
E250K substitution and 1 patient of a glutamic acid 257 (GAG) $\rightarrow$ lysine (AAG)/p.Glu250Lys/E257K substitution in exon 11 of the PSTPIP1 gene. MRP8/MRP14 concentrations were extremely elevated in these patients $(0.9$ $12 \mathrm{~g} / \mathrm{l})$ compared to eleven patients presenting with classical PAPA symptoms (0.02-0.35 g/l), whose levels again were significantly higher compared to normal controls. Cytokine profiling confirmed the heterogeneity of PSTPIP1 mutations with a distinct profile for the $\mathrm{Hz} / \mathrm{Hc}$ phenotype. MRP8/14 hypersecretion was found in PBMCs of patients with PSTPIP1 mutations and the serum of patients with active disease showed costimulatory properties on monocytes activated with TLR-1 ligands.

\section{Conclusion}

The novel PSTPIP1 E250K and E275K mutations cause an autoinflammatory disorder known as hyperzincaemia and hypercalprotectinaemia. The disease causes a heterogeneous spectrum of symptoms that only partially overlaps with the presentation of the classical PAPA syndrome. Elevated MRP8/14 levels are a common hallmark and biomarker of disorders caused by mutations in the PSTPIP1 gene.

\section{Disclosure of interest}

None declared.

\section{Authors' details}

${ }^{1}$ Institute of Immunology, University Hospital Muenster, Germany. 2Department of Paediatric Rheumatology and Immunology, University Children's Hospital Muenster, Muenster, Germany. ${ }^{3}$ Department of Clinical Chemistry Großhadern, University Munich, Munich, Germany. ${ }^{4}$ Department of Pediatric Immunology, University Medical Centre Utrecht, Utrecht, The Netherlands. ${ }^{5}$ National Institute of Allergy and Infectious Diseases, National

\section{Biomed Central}


Institute of Health, Bethesda, USA. " 2 nd Division of Pediatrics, "G. Gaslini" Scientific Institute, Genova, Italy. ${ }^{7}$ Department of Immunology, Dr. Negrín University Hospital, Las Palmas de Gran Canaria, Spain. ${ }^{8}$ Immunology Department-CDB/IDIBAPS, Hospital Clinic, Barcelona, Spain. ${ }^{9} 3$ rd Department of Pediatrics, Athens University Medical Faculty, Athens, Greece. ${ }^{10}$ Service de Génétique Médicale, Centre Hospitalo-Universitaire, Nantes, France.

${ }^{11}$ Department of Pediatrics and Neonatology, Nagoya City University,

Nagoya, Japan. ${ }^{12}$ Department of Gastroenterology, Infectious Diseases and Rheumatology, Charité University Hospital Berlin, Berlin, Germany.

${ }^{13}$ Department of Pediatrics, Stanford University Medical Center, Stanford, LA, USA. ${ }^{14}$ Division of Clinical Immunology and Allergy, Children's Hospital Los Angeles, LA, USA. ${ }^{15}$ Deutsches Zentrum für Kinder- und Jugendrheumatologie, Garmisch-Patenkirchen, Germany. ${ }^{16}$ Department of Clinical Chemistry, Charing Cross Hospital, London, UK. ${ }^{17}$ Department of Dermatology, University Hospital Muenster, Muenster, Germany. ${ }^{18}$ National Institute of Arthritis and Musculoskeletal and Skin Diseases, National Institute of Health, Bethesda, USA.

Published: 8 November 2013

doi:10.1186/1546-0096-11-S1-A158

Cite this article as: Holzinger et al:: PW02-018 - Impact of PSTPIP1

mutaions on clinical phenotype. Pediatric Rheumatology 2013

11(Suppl 1):A158.

\section{Submit your next manuscript to BioMed Central} and take full advantage of:

- Convenient online submission

- Thorough peer review

- No space constraints or color figure charges

- Immediate publication on acceptance

- Inclusion in PubMed, CAS, Scopus and Google Scholar

- Research which is freely available for redistribution

Submit your manuscript at www.biomedcentral.com/submit
(Ciomed Central 